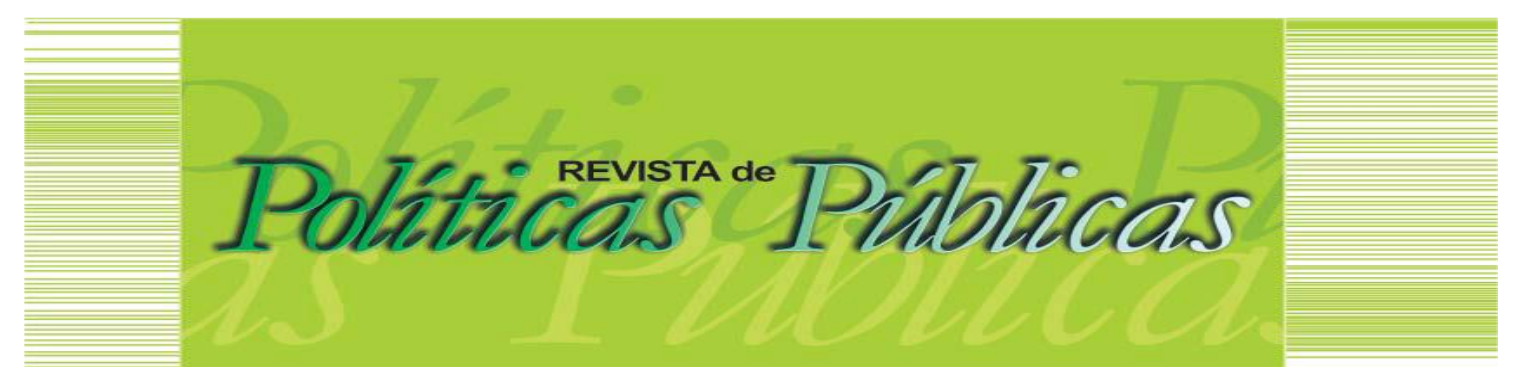

\title{
TRABALHO, PUNIÇÃO E POLITICA SOCIAL: notas sobre a gestão da miséria e da violência no capitalismo periférico tardio
}

Matheus Boni Bittencourt ${ }^{1}$

\begin{abstract}
Resumo:
Este artigo visa compreender, por meio de pesquisa bibliográfica e documental e abordagem da sociologia histórica, as mudanças, no Brasil pós-autoritário, das instituições do trabalho e da punição sobre os processos de acumulação flexível e global, de um lado, e de endurecimento punitivo, de outro. Evidencia que, no Brasil, historicamente, o desenvolvimentismo, em versões mais ou menos democráticas ou autoritárias, populistas ou conservadoras, estruturou uma cidadania estratificada. Conclui, ainda, que a transição democrática inaugurou uma concepção universalista e igualitária da cidadania, cuja implementação foi limitada tanto pela tradição autoritária quanto pela ortodoxia macroeconômica. Dessa maneira, 0 Brasil combinou inclusivismo e punitivismo, uma contradição latente que explodiu em conflito aberto com a dissolução da coalizão lulista na crise política e econômica da década de 2010.
\end{abstract}

Palavras-chave: Cidadania. Trabalho. Punição. Política social.

WORK, PUNISHMENT AND SOCIAL POLICY: notes on the management of misery and violence on late peripherical capitalism

\section{Abstract:}

This article goal is to understand, by bibliographic and documental research and the approach of historical sociology, the changes in the post-authoritarian Brazil of labor and penal institutions under the processes of flexible and global accumulation, on the one hand, and punitive hardening, on the other. In Brazil, historically, the developmentalism, in more or less democratic or authoritarian versions, populist or conservative ways, structured a stratified citizenship. The democratic transition inaugurated a universalist and egalitarian conception of citizenship, whose implementation was limited by both authoritarian tradition and macroeconomic orthodoxy. In this way, Brazil combined inclusivism and punitivism, a latent contradiction that exploded in open conflict with the dissolution of the lulist coalition into the economical and political crises of 2010s years.

Keywords: Citzenship. Labour. Punishment. Social Policy.

Artigo recebido em: 21/01/2019 Aprovado em: 04/04/2019. DOI: http://dx.doi.org/10.18764/2178-2865.v23n1p246-267.

\footnotetext{
1 Graduado em Ciências Sociais. Doutorando em Sociologia pela Universidade Federal do Rio Grande do Sul (UFRGS). Especialista em desenvolvimento humano no governo do Espírito Santo. Pesquisador do Grupo de Pesquisa Violência e Cidadania. Endereço: Rua Luiz Gonzalez Alvarado s/n- Enseada do Suá, Vitória - ES. CEP: 29050-380. E-mail: matheusb2@yandex.com
} 


\section{INTRODUÇÃO}

O objetivo deste artigo é analisar a conexão entre trabalho, punição e política social no capitalismo brasileiro contemporâneo. Primeiramente procedemos a uma discussão teórica, a partir das contribuições clássicas e contemporâneas, da teoria da punição de Durkheim aos debates atuais sobre acumulação flexível e enrijecimento penal, passando pelo período de regulação fordista-taylorista e seu defensivismo social. A seguir, enfocamos o processo de vinculação entre trabalho e punição no Brasil, utilizando pesquisa bibliográfica e documental, cujas fontes incluíram de legislação, programas (BRASIL, 2000, 2007) e estatísticas oficiais (BRASIL, 2006, 2012, 2013a, 2013b; INSTITUTO BRASILEIRO DE GEOGRAFIA E ESTATÍSTICA, 2015) a inquéritos parlamentares (BRASIL, 2009) ${ }^{1}$ e obras literárias de valor documental (SOARES, 2000; LINS, 2007; VARELLA, 2005, 2012, 2017). A análise desenvolvida com base nessas fontes enquadra-se em uma perspectiva institucionalista histórica (HALL; TAYLOR, 2003).

Apesar de sofrer a influência e impacto dos processos socioeconômicos e político-penais dos países capitalistas centrais, o passado colonial-escravista e a posição periférica na economia internacional condicionaram peculiaridades à trajetória brasileira. 0 período fordista-taylorista correspondeu, no Brasil, a um esforço nacional de modernização industrial retardatária e dependente, baseado na substituição de importações, em versões mais ou menos populistas ou elitistas, democráticas ou autoritárias, com suas correspondentes táticas de integração social e coerção policialpenal. A crise do modelo de substituição de importações e a transição democrática, nos anos 1980, e a inserção subordinada à globalização, nos anos 1990, reconfiguraram os termos do dilema: de uma cidadania estratificada para uma tensão entre inclusivismo e punitivismo dentro das coalizões governantes entre 2003 e 2014, que reuniam correntes políticas diversas. Contradição latente que explodiu em conflito aberto com a crise econômica e política a partir de 2015.

\section{TRABALHO, PUNIÇÃO E CAPITALISMO}

A relação entre trabalho e punição foi observada na Sociologia Clássica de diferentes perspectivas. De maneira geral, as concepções da organização do trabalho e dos dispositivos punitivos tinham uma estreita correspondência entre si. A sociologia da ordem considerou as punições como rituais, e os desvios como sintomas de desintegração social, considerando o trabalho como um mecanismo de integração social. A sociologia conflitual, por outro lado, vinculou as práticas punitivas à dominação social e o desvio como uma expressão da conflitualidade, considerando o trabalho como organizado de maneira histórica, com destaque para as formas de exploração (na teoria crítica, alinhada à economia marxista) ou de competição por recursos escassos no mercado (no paradigma weberiano, 
mais próximo ao marginalismo). Em comum, ambas as teorizações partiam de uma ruptura com a concepção oficial, segundo a qual a função primordial da punição é dissuadir e controlar os criminosos, reduzindo a criminalidade por meio de intimidação de criminosos em potencial e ressocialização, incapacitação ou eliminação de criminosos em ato.

Segundo Émile Durkheim (1973), as práticas punitivas eram rituais expressivos, que reproduziam os elementos de integração social implícita na organização social do trabalho, mediante a afirmação punitiva de crenças coletivas ofendidas pelo desviante. Tais crenças, que se fundavam em mecanismos de integração social, eram correspondentes a determinados níveis de diferenciação funcional da estrutura social. Formulando dois tipos extremos, Durkheim (1973) classificara algumas sociedades, nas quais prevalecia uma baixa divisão do trabalho e diferenciação funcional, como de solidariedade mecânica. Tal solidariedade tinha como fundamento a homogeneidade moral entre os seus integrantes, e uma reação violentamente punitiva contra todos os desviantes. Sociedades com alto nível de diferenciação funcional eram caracterizadas, segundo Durkheim, como de solidariedade orgânica, na qual o fundamento da integração social era a interdependência universal: cada indivíduo, em condições normais e não patológicas, teria um papel bem definido e delimitado, ainda que relativamente móvel, contribuindo parcialmente para a produção de uma ordem social e política da qual ele, como ínfima parte de um todo muito maior, dependia estreitamente. As reações ao desvio, sob esta solidariedade orgânica, tenderiam a maior suavidade, especialização e formalização, levando à minimização das punições físicas e à ampliação dos mecanismos judiciais de restauração e compensação, em detrimento da violência contra os desviantes. A administração da justiça, ao invés de difusa pela comunidade e dependente da sua coesão moral e religiosa, seria mais uma função especializada, a cargo de especialistas empregados pelo Estado, este definido como um grande cérebro social. Favorecidas, assim, as condições sociais do individualismo, o risco de uma anomia aguda exigiria novas instituições de controle social, entre as quais Durkheim punha em destaque a escola universal e laica, capaz de ministrar conteúdos científicos e normatividades que escapariam às capacidades da educação privada propiciada pela família, e as corporações de ofício, que além de negociação de condições e remuneração de trabalho, deveriam propiciar um sentido de pertencimento e solidariedade profissional, atuando como organizações intermediárias entre o indivíduo e o Estado (DURKHEIM, 1973).

A conexão entre as instituições penais e a organização do trabalho foi ressaltada, de maneira aparentemente independente de Durkheim, pelos alemães Georg Rusche e Otto Kirschheimer (1999). Porém, num sentido diverso daquele preconizado pelo sociólogo francês: a conexão se daria não apenas no nível de diferenciação funcional, embora a este remetesse também, de maneira indireta e subordinada, pois o principal seria a correspondência entre os mecanismos punitivos e o modo de produção. A ideia de modo de produção é mais complexa que a de divisão do trabalho, pois inclui a 
produtividade social do trabalho e a estrutura de propriedade dos meios de produção. Em outras palavras, a divisão do trabalho não teria apenas um caráter de integração social, contribuindo para difundir a interdependência universal por meio da diferenciação social, como também um caráter de relação de poder e conflito, na medida em que permitiria a apropriação parcial dos produtos do trabalho alheio. Inicialmente por meio da coerção direta, pessoal ou religiosa (impostos, trabalhos forçados etc), e, posteriormente, disfarçada por meio do contrato de trabalho assalariado, formalmente livre e igualitário. Assim, o aprofundamento da divisão do trabalho não teria necessariamente o caráter de uma pacífica progressão rumo à diferenciação funcional e interdependência universal, porém assumindo um caráter muitas vezes estratégico, quando observado num nível da unidade de produção, como as fábricas. A história da divisão intraempresarial do trabalho mostra como essa nem sempre obedeceu a critérios de pura eficiência tecnológica, e menos ainda de integração social dos empregados, havendo, na verdade, uma utilização da divisão do trabalho como instrumento organizacional de subjugação dos agentes imediatos do processo de trabalho. (MARGLIN, 1980).

O mesmo é observável em relação ao emprego extensivo e intensivo da maquinaria e do controle do tempo de trabalho, e até do tempo de lazer dos operários assalariados. (THOMPSON, 1998; MARX, 2006). Fica assim questionado o suposto estatuto científico e neutralidade de uma ciência da administração que busca aumentar a produtividade, mas também estimular a submissão disciplinada e obediente dos trabalhadores empregados no interior de cada empresa, e em um nível nacional a colaboração de classes sob a supremacia do empresariado capitalista. (DECCA, 1984; NEFFA, 1990). No entanto, essa disciplina no interior do processo de trabalho jamais prescindiu de uma disciplina externa ao trabalho, imposta por meio de processos de penalização seletiva, mobilizando um aparato estatal cujas bases eram recrutadas entre a própria classe trabalhadora (exército e polícia) e subordinado à alta burocracia do Estado.

Rusche e Kirchheimer, como Durkheim, rechaçavam as funções oficiais da pena como dissuasão e controle sobre os criminosos, com vistas à redução do crime violento. Porém, aceitavam outro tipo de instrumentalidade do direito penal: a política. A lei criminal passa a ser vista, então, como um recurso estratégico das classes dominantes para o controle coercitivo da força de trabalho. De fato, para Rusche (no que Kirschheimer o seguiu) a penalidade não era uma técnica de controle do crime, e sim uma estratégia de sujeição dos trabalhadores, com o objetivo de assegurar a exploração do trabalho e suprimir tanto os efeitos indesejados quanto as tentativas conscientes de subversão da ordem dominante. Teria sido assim no feudalismo, quando o direito consuetudinário fora utilizado pela nobreza feudal para a sujeição do campesinato, tendo como instrumento principal as punições físicas e o confisco de bens. E persistia assim, sob o capitalismo, com a maior centralidade do encarceramento como medida punitiva (e não apenas cautelar). 
Inicialmente, dada a relativa escassez de força de trabalho livre, uma das principais funções do cárcere era fornecer trabalho escravo à indústria, mediante o encarceramento de vadios e pequenos criminosos. Com a consolidação do capitalismo, o cárcere tornou-se a punição padrão e oscila entre funções de controle e ressocialização e funções de dissuasão e neutralização. A distinção entre ambas se daria por grau, já que são apenas variações do mesmo dispositivo, o encarceramento. 0 princípio regulador da dureza do cárcere seria a less elegibility, segundo o qual as condições de vida dentro da prisão serão sempre inferiores às piores condições de vida fora da prisão. Assim, no contexto de uma superpopulação relativa, a repressão assume um caráter abertamente violento, de maior desprezo pela vida, no sentido de eliminar ou incapacitar indivíduos considerados supérfluos ou ameaçadores para a manutenção da ordem política, da propriedade privada e da acumulação de capital.

Esse funcionamento das instituições penais não seria uma expressão ou epifenômeno, mas um mecanismo que de fato teria contribuído para a ascensão e a reprodução do capitalismo. Não expressaria a penalidade a integração social, e sim a lógica implacável da dominação e exploração, aplicada não a todos os cidadãos, e sim àqueles mais marginalizados ou rebeldes dentre os explorados como força de trabalho pelas classes dominantes e proprietárias.

Apesar das suas evidentes virtudes, essa análise deixa de fora especificamente dois aspectos que estavam em primeiro plano na teoria durkheimiana: primeiramente, as dimensões simbólicas e organizacionais da punição, que apesar de muitas vezes violenta, não pode ser reduzida a simples coerção física direta, pois encerra conteúdos culturais e expressivos. E o caráter crescentemente formalizado, especializado e estatizado da coerção punitiva, legalmente monopolizada pelo Estado moderno. Essas lacunas derivam da menor atenção dada à organização interna das instituições carcerárias e sua relação com a organização do processo de trabalho. (RUSCHE; KIRCHHEIMER, 1999).

Coube a Michel Foucault $(2003,2009)$ a atenção a esses aspectos e uma análise capaz de conjugar os elementos: uma análise dos conteúdos culturais e funções políticas da punição, pensada como ritual simbólico sobre o corpo e a alma, e como instrumento organizacional de controle sobre uma força de trabalho explorável para fins de acumulação de capital. Apesar do pioneirismo de Rusche, ao analisar a relação externa entre a organização econômica e as instituições punitivas, foi Foucault quem primeiro se deteve sobre a organização interna das formas de castigo com a mesma atenção e detalhe que Marx dispensara à organização fabril, encontrando até mesmo uma analogia profunda entre a prisão e a fábrica. Assim, se a fábrica, como protótipo da organização capitalista do trabalho em geral, tendia a esvaziar e desarticular o controle do trabalhador sobre o processo de produção, reduzindo cada produtor individual a um órgão da maquinaria tecnológica e econômica de acumulação de capital, também o prisioneiro era cada vez mais submetido a uma estrita disciplina organizacional e judiciária que regulava 
seus horários, deslocamentos, atividades e interações sob uma estrita vigilância, até o ponto em que a internalização do olhar que tudo vigia dispensasse até mesmo a existência de um vigia real, como no panopticon de Bentham. A prisão e a fábrica passam a ser consideradas, ao lado ainda das instituições educacionais, militares e medicinais, como mecanismos institucionais de uma rede descentralizada de micropoderes que são operados no cotidiano por diversos agentes, modelando subjetividades disciplinadas, chegando ao ponto de tornar útil e funcional ao exercício do poder burguês a própria criminalidade, incorporada às estratégicas e táticas micropolíticas mediante a gestão de ilegalismos. A relação entre o cárcere e a fábrica foi aprofundada, pouco depois, por Melossi e Pavarini (2006), que compararam os diferentes modelos penitenciários existentes na Itália e nos Estados Unidos no século XIX.

\section{FORDISMO-TAYLORISMO E DEFESA SOCIAL}

O taylorismo e o fordismo se desenvolveram como uma reformulação dos processos industriais por uma administração supostamente científica da produção, no sentido de maior verticalidade, concentração e padronização do trabalho. A mecanização e automação industriais foram usadas para centralizar ao máximo o conhecimento aplicado ao processo produtivo na direção empresarial, subordinando o trabalhador a um ritmo intenso de tarefas repetitivas e fracionadas ao máximo. A produção em massa, por sua vez, exigia um consumo (público e privado) em massa e uma certa padronização sociocultural, o que só podia ser realizado por meio do planejamento estatal. (CASTEL, 1998; HARVEY, 1992; NEFFA, 1990).

O aprofundamento da racionalização e subordinação real do trabalho ao capital, expressa e estimulada por vias ideológicas pelo taylorismo, foi mais ou menos concomitante à maior burocratização das forças policiais e consolidação das instituições penais. Enquanto o trabalho coletivo era decomposto em movimentos, tempos e localizações padronizados, com crescente intensidade do ritmo de trabalho, remuneração individualizada pela produtividade e padronizada por tarefa e especialização e profissionalização dos operários, a força policial conhecia um processo de profissionalização e especialização, voltada cada vez mais para a repressão criminal e manutenção da ordem pública contra distúrbios coletivos, tornando-se um corpo permanente de funcionários especializados e selecionados segundo um modelo ao mesmo tempo militarizado e punitivo. Essa simultaneidade pode ser observada nos Estados Unidos com uma certa precisão: o estabelecimento de departamentos de polícia com pessoal permanente, recrutado e treinado de maneira mais profissional, ocorre mais ou menos em simultâneo às mudanças do processo de trabalho que fizeram aumentar a produtividade e a intensidade 
do trabalho. $O$ país de origem do taylorismo também ajudou a forjar a polícia no sentido moderno do termo (BAYLEY, 2001; DIAS NETO, 2003; NEFFA, 1990).

É claro que, como mostrou Harvey (1992), a implantação de um regime de acumulação ou modo de regulação adequado ao sistema de trabalho taylorista-fordista foi tudo, menos automática, e decorreu de intensos conflitos políticos, tanto internos quanto internacionais. A solução fascista, por exemplo, subordinou e hierarquizou a força de trabalho por meio de uma repressão terrorista e regulamentos corporativistas, atrelando a organização dos trabalhadores ao Estado ditatorial, de um lado, eliminando lideranças dissidentes por meio do encarceramento, escravidão e extermínio, e impondo pesados sacrifícios às massas por meio de políticas de expansionismo militar e segregação racial. Já o New Deal, embora sem prescindir da repressão policial (e convivendo com uma segregação racial tradicional), tentou mantê-la como último recurso e desenvolver um controle negociado, pelo qual o aparato estatal serviu para a garantia dos acordos de concessões mútuas entre o capital e o trabalho no seio da grande indústria, além de suplementar o consumo individual das famílias operárias com serviços sociais. O modelo do New Deal, com algumas variações nacionais, serviu de exemplo para os regimes liberal-democráticos que sobreviveram (Inglaterra) ou emergiram das Guerras Mundiais (França, Alemanha, Japão, Itália etc). Apesar das diferenças ideológicas e culturais entre estes países, há uma certa convergência entre eles no sentido de estabelecimento de um pacto social mediado pela burocracia estatal, pelo qual a crescente produtividade do trabalho devia beneficiar em parte os próprios trabalhadores, por meio de aumentos de salários individuais e sociais (seguridade social), sem prejudicar seriamente a lucratividade capitalista. As concessões mútuas, no benefício da estabilidade e do crescimento econômico, permitiriam a difusão hierarquizada de benefícios do progresso técnico e econômico, criando uma sociedade que, se não era igualitária, ao mesmo garantia um consumo de massa e esperança de melhoria contínua do padrão de consumo. Assim, a política econômica e social keynesiana buscava ampliar de maneira equilibrada os dois motores do crescimento econômico: a ampliação da produtividade do trabalho e o crescimento da demanda efetiva. Como parte disso, a política penitenciária foi reformulada no sentido de um investimento na ressocialização, encarando a terapêutica penal como uma maneira de incluir o ex-detento na sociedade do trabalho assalariado. Isso favoreceu o que Garland (2008) chamava de previdenciarismo penal (penal welfarism), e as falhas nos objetivos de reintegração dos condenados ao mundo do trabalho eram retoricamente neutralizadas como insuficiência de investimento e de capacidade técnica, que poderiam ser sanadas futuramente, com a ampliação da capacidade de investimento do Estado keynesiano. Ou seja, a falha estaria na falta temporária de recursos necessários para a implementação adequada dos propósitos de ressocialização. (GALARND, 2008). 
O modelo keynesiano-fordista de integração social, entretanto, não era universal ou igualitário, e por isso não prescindia de alguma dose de arbitrariedade policial nos seus elos fracos. Para começar, a força de trabalho incluída era bastante específica: masculina, branca e sindicalizada. $O$ que implica na marginalização econômica e social mais ou menos forte da força de trabalho feminina e de minorias étnicas e nacionais e outros grupos não ajustados à disciplina de trabalho exigida pelo fordismo, o que expunha esses grupos excluídos a maior repressão, seja a nível de costumes (dominação masculina na família nuclear patriarcal) ou do uso da força policial contra integrantes das minorias étnicas e nacionais. Além disso, a hegemonia da negociação coletiva, se favorecia a inclusão dos assalariados bem organizados via ativismo sindical reformista, exigia que a radicalização trabalhista fosse perseguida e suas manifestações reprimidas, ainda que nem sempre postas na ilegalidade total. Do mesmo modo que assumiu a seguridade e ajuda sociais de maneira hegemônica, o Estado keynesiano-fordista centralizou e hegemonizou responsabilidade pela manutenção da ordem social e defesa da propriedade. As organizações policiais burocratizadas, segundo critérios repressivos e militarizados, foram, assim, direcionadas para a proteção da propriedade (pública e privada) e para 0 controle dos segmentos social e economicamente marginalizados e/ou politicamente radicalizados da sociedade. Em países centrais essa conflitualidade foi localizada em grupos minoritários, ainda que significativos, como os negros estadunidenses. Mas na periferia da economia-mundo, os marginalizados incluíam a imensa maioria da população. (CASTEL, 1998; HARVEY, 1992).

\section{NOVA QUESTÃO SOCIAL E TOLERÂNCIA ZERO}

Com a crise do regime de acumulação keynesiano-fordista, foram detonadas ou aceleradas algumas transformações no mundo do trabalho. Essas mudanças se subordinaram às reestruturações industrial e estatal, que, respectivamente, são consideradas como a implementação de um pós-fordismo no interior das empresas capitalistas e na reformulação neoliberal da estrutura e funções dos Estados capitalistas. A reestruturação industrial se traduziu pela maior flexibilidade e descentralização do processo produtivo. Um dos principais impactos a nível social foram o aumento do desemprego e da precarização do emprego e do trabalho, a restrição e reformulação das políticas sociais e o aumento da insegurança social e da penalização das camadas marginalizadas da sociedade (ANTUNES, 2004; 2009; CASTEL, 1998; DE GIORGI, 2006; GARLAND, 2008; GOUNET, 1999; WACQUANT, 2001a, 2001b, 2007, 2008).

Os modelos pós-fordistas de produção, com destaque para o toyotismo, primaram pela flexibilização do contrato e dos processos de trabalho, por vários instrumentos, que variaram de país para país e de um setor para o outro. Entre esses dispositivos, o modelo da indústria automobilística japonesa trouxe a produção por demanda, o trabalho em equipe e a descentralização industrial, tanto por 
deslocamento espacial quanto pela subcontratação de funções intermediárias ou secundárias. 0 sucesso da indústria automobilística japonesa estimulou a adaptação desse modelo para empresas de outros países que sofriam a sua concorrência, além de outros setores industriais. A produção industrial foi reorganizada como uma rede descentralizada de empresas e de equipes dentro de cada empresa, produzindo peças sob demanda ao invés de produzir em massa para estoques que apenas depois eram vendidas. Foi, sobretudo, uma reestruturação organizacional do trabalho. As tecnologias de automação, informática, transporte e telecomunicações são utilizadas de maneira intensiva, porém se subordinam à organização do trabalho, não devendo ser atribuída à tecnologia o primado sobre a organização social da produção. (GOUNET, 1998).

Segundo Castel (1998), a flexibilização da produção tem formas internas e externas. A flexibilidade interna é a seleção e treinamento do pessoal empregado para a polivalência e versatilidade, o que exige uma verdadeira revolução gerencial e educacional que prepare a força de trabalho para 0 envolvimento nas práticas de trabalho flexíveis. Porém é por si mesma excludente, na medida em que leva a uma super seleção dos empregados, favorecendo aqueles que têm oportunidade de preparação e experiência muito acima da média e excluindo duramente os que estão abaixo dela. A flexibilização externa é a subcontratação de trabalhadores ou de serviços e produtos por empresas outras pela empresa principal, articulando uma rede descentralizada e flexível de fornecedores de produtos, serviços e mão de obra, uma prática que também favorece a precarização. Isso porque, de um lado, promove a fragmentação da força de trabalho, que daí enfrenta dificuldades maiores para se organizar, reivindicar e negociar coletivamente, e de outro, a descentralização permite que as empresas secundárias se instalem em regiões (em níveis infranacionais ou internacionais) nos quais há menor custo com a mão de obra, impostos e regulamentações. Ocorre, assim, uma desestabilização dos estáveis que amplia as zonas de marginalização do mundo do trabalho, levando a uma crescente polarização e segmentação do trabalho. Num polo os grupos profissionais de alta renda e qualificação, capazes de aproveitar-se de nichos que exigem uma formação tecnológica e cultural diferenciada, além de discriminação positiva (por gênero, etnia ou nacionalidade) pelos empregadores. De outro, segmentos que competem entre si por empregos de baixo salário, instáveis ou temporários, com intensidade ou duração ampliada da jornada, afetando principalmente os de qualificação abaixo da média, mulheres, jovens e etnias estigmatizadas. Apesar do denominador comum da precarização, esses empregos e empregados são bastante heterogêneos entre si, ao contrário da relativa homogeneização do operariado fordista.

O resultado não é só um aumento do desemprego e do emprego precário, como também uma deterioração das condições de trabalho (jornadas mais longas, menor proteção social, insalubridade, insegurança etc.) e desvalorização simbólica. Enfim, a precarização atinge o corpo e a alma do trabalhador, e compromete a sua integração social. E para favorecer e acelerar a 
reestruturação, em nome da competitividade, há uma reformulação do próprio Estado. À flexibilização microeconômica (ao nível das unidades de produção) vinculou-se uma financeirização macroeconômica, uma restrição social e expansão penal dos Estados. Despesas sociais foram cortadas por vias legais, administrativas e contábeis, programas sociais deixaram de ser universais ou vinculados ao trabalho formal para serem orientados para grupos de risco, os mesmos que passaram a receber uma vigilância mais ostensiva e intensa das forças policiais. O reforço das penalidades se deu por meio de legislações endurecidas e utilizadas de maneira discricionária pela polícia e justiça, embaladas no discurso políticomidiático da tolerância zero. 0 ideal de ressocialização foi abandonado, em favor de uma concepção belicista de segurança pública como combate a inimigos internos. Mesmo postulados liberais clássicos, como a individualização legal das condutas criminais e a presunção de inocência, foram enfraquecidos em favor de uma ideologia de gestão seletiva de riscos criminais que na prática contribui para converter camadas sociais inteiras em suspeitos até que se prove o contrário. Ou, pelo menos, essa foi a estratégia originalmente implementada pelas elites políticas liberal-conservadoras. (WACQUANT, 2007).

Apesar de muitos países manterem uma parte da proteção social herdada do keynesianismo-fordismo, o princípio geral da política social passa a priorizar a administração das consequências extremas do liberalismo, ao invés do combate à desigualdade social. Dentre as formas variadas de gestão estatal das consequências do funcionamento do mercado, podemos mencionar o modelo de inserção francês, que lança mão de uma gestão focalizada por estrato social e território, combinando políticas sociais focadas e reforço da vigilância policial (muitas vezes discriminatória) no sentido de uma amenização das piores consequências da precarização. (CASTEL, 1998; WACQUANT, 2007, 2008). E o modelo do workfare estadunidense, centrada na ajuda social condicionada pelo trabalho obrigatório e na hiper-expansão do punitivismo seletivo que tornou os EUA o líder mundial de encarceramento. (WACQUANT, 2001a, 2001b, 2007).

\section{DEMOCRATIZAÇÃO, INCLUSIVISMO E PUNITIVISMO NO BRASIL}

O simples transplante das análises sobre a relação entre trabalho e punição nos países capitalistas centrais (DI GIORGI, 2006; FOUCAULT, 2013; RUSCHE; KIRSCHHEIMER, 1999; YOUNG, 2002; WACQUANT, 2007) seria uma violência aos fatos da realidade brasileira. No entanto, é possível tomar tais análises como hipóteses a serem contrastadas e reformuladas no contexto brasileiro. Não se trata de um procedimento que duplica a divisão centro/periferia numa esfera intelectual, com os países centrais como produtores de teorias sociais, e os pesquisadores das regiões periféricas como testadores locais. O procedimento, pelo contrário, busca uma reformulação e invenção, apontando os limites das referidas análises, como também suas potencialidades heurísticas, buscando construir uma concepção mais abrangente da relação entre trabalho e punição nas sociedades capitalistas. Tentamos resumir a 
trajetória político-penal na Tabela 1.

Tabela 1 - Trajetória histórica da gestão da pobreza e da violência

\begin{tabular}{|c|c|c|c|}
\hline Pe ríodo & Base Econômica & Política Social & Política penal \\
\hline Im pé rio & $\begin{array}{l}\text { Escravis mo primário- } \\
\text { exportador }\end{array}$ & $\begin{array}{l}\text { Cliente lismo e } \\
\text { f lantropia }\end{array}$ & $\begin{array}{l}\text { Punições corporais } \\
\text { públicas e privadas }\end{array}$ \\
\hline Re pública Ve lha & $\begin{array}{l}\text { Capita lis mo a grário } \\
\text { primário-e xportador }\end{array}$ & $\begin{array}{l}\text { Cliente lismo e } \\
\text { f lantropia }\end{array}$ & $\begin{array}{l}\text { Repressão à } \\
\text { vadiagem e a o } \\
\text { sindica lis mo; prisão } \\
\text { como principal } \\
\text { prática punitiva }\end{array}$ \\
\hline $\begin{array}{l}\text { Estado Novo (1935- } \\
1945)\end{array}$ & $\begin{array}{l}\text { Industria lização por } \\
\text { substituição de } \\
\text { importações dirigida } \\
\text { pelo Estado }\end{array}$ & $\begin{array}{l}\text { Leis trabalhistas e } \\
\text { seguridade } \\
\text { vinculadas ao } \\
\text { e mprego formal; } \\
\text { subordinação do } \\
\text { sindicalismo ao } \\
\text { governo federal }\end{array}$ & $\begin{array}{l}\text { Previdenciaris mo } \\
\text { penal restrito; } \\
\text { repressão à } \\
\text { vadiagem e a os } \\
\text { "subversivos" } \\
\text { (comunistas, } \\
\text { anarquistas...) }\end{array}$ \\
\hline $\begin{array}{l}\text { Democracia } \\
\text { populista (1946- } \\
1964)\end{array}$ & & $\begin{array}{l}\text { Ampliação da } \\
\text { margem para } \\
\text { reivindicação e } \\
\text { a plicação } \\
\text { trabalhistas }\end{array}$ & $\begin{array}{l}\text { Abrandamento da } \\
\text { perseguição a os } \\
\text { "subversivos" }\end{array}$ \\
\hline $\begin{array}{l}\text { Dita dura Civil-Milita r } \\
(1964-1985)\end{array}$ & & $\begin{array}{l}\text { f exibilização } \\
\text { trabalhista; f m da } \\
\text { estabilida de; criação } \\
\text { do FGTS; a rrocho } \\
\text { sa larial; sindica lis mo } \\
\text { subordinado a o } \\
\text { governo fe de ral; } \\
\text { BNH; cré dito } \\
\text { educativo }\end{array}$ & $\begin{array}{l}\text { Militarização do } \\
\text { controle social, } \\
\text { especialmente de } \\
\text { pobres e opositores; } \\
\text { guerra às drogas }\end{array}$ \\
\hline $\begin{array}{l}\text { De mocracia } \\
\text { presidencialista de } \\
\text { coalizão }\end{array}$ & $\begin{array}{l}\text { Inserção subordinada } \\
\text { a o capitalismo global } \\
\text { sob hegemonia do } \\
\text { setor financeiro }\end{array}$ & $\begin{array}{l}\text { Sistema Único de } \\
\text { Saúde; terceirizações } \\
\text { de empregos e de } \\
\text { serviços públicos; } \\
\text { Bolsa-Fam ília/CadÚni } \\
\text { co; MCMV }\end{array}$ & $\begin{array}{l}\text { Leis: dos crimes } \\
\text { hediondos; de } \\
\text { Drogas; de } \\
\text { Organizações } \\
\text { Criminosas; do } \\
\text { Estatuto do } \\
\text { Desarmamento; } \\
\text { Maria da Penha; } \\
\text { Antite rrorismo }\end{array}$ \\
\hline
\end{tabular}

Fonte: Elaborada pelo autor.

Depois da prevalência de um liberalismo repressivo na República Velha, quando a questão social é caso de polícia, a relação entre legislação criminal e trabalhista pode ser localizado inicialmente na Era Vargas, quando a Consolidação das Leis do Trabalho (Lei $n^{0} 5452$, de $1^{0}$ de maio de 1943) e 0 código penal (Lei n 2848 de 7 de dezembro de 1940) e de processo penal (Lei $n^{0} 3689$ de 3 de outubro de 1941) foram decretados sob o Estado Novo, e, nas décadas seguintes, foram várias vezes reformulados em função da conjuntura política e econômica. Se em relação à República Velha a legislação trabalhista marcou uma inovação significativa, porém, de alcance inicialmente restritivo, por 
ser aplicável apenas a trabalhadores com emprego formal de profissões reconhecidas pelo Estado, a legislação criminal serviu como reforço disciplinar a tais práticas, complementando os benefícios sociais do emprego formal com a repressão policial aos vadios, grevistas e trabalhadores informais. Mais que um contrato, o emprego formal foi estabelecido como requisito para a cidadania para os que não possuíam educação superior, laços pessoais com autoridades políticas ou propriedades rentáveis. 0 hábito adquirido por amplas camadas populares de andar com a carteira de trabalho assinada nos bolsos, para se apresentar como trabalhadores honestos sempre que abordados pela polícia, é um exemplo interessante de como 0 direito penal e o direito trabalhista foram combinados de maneira paradoxal, produzindo uma cidadania diferenciada, calcada na lógica do privilégio profissional regulamentado. (SANTOS, 1979). O que, no final das contas, conquistou considerável legitimidade popular, a ponto de tornar-se senso comum a diferenciação informal entre os brasileiros cidadãos e os brasileiros marginais². (HOLSTON, 2013). Buscava-se a integração subordinada dos trabalhadores assalariados urbanos ao projeto nacional-desenvolvimentista, numa sociedade em processo de industrialização e urbanização, mas que mal acabara de abolir a escravidão legal, com o Estado administrando a repressão policial com uma mão e a concessão de benefícios sociais aos empregados formalizados com a outra.

A primeira flexibilização das leis trabalhistas no Brasil veio durante os Anos de Chumbo, extinguindo a estabilidade no emprego e criando mecanismos compensatórios, entre outras modificações ${ }^{3}$, e combinou-se com um controle repressivo extremo sobre a atividade sindical, na prática, esvaziando um importante instrumento de efetivação dos direitos trabalhistas. (HOLSTON, 2013).

De acordo com a retórica da elite governamental, tratava-se com o movimento de 1964, de criar condições para um desenvolvimento mais balanceado e justo da economia de mercado, afastados aqueles grupos que, de acordo com a versão oficial, buscavam substituir a ordem econômica e social prevalecente no Brasil (SANTOS, 1979, p. 102)

O regime ditatorial de 64-85 perseguiu, em aliança com grandes empresas privadas e estrangeiras, uma política de industrialização por substituição de importações - uma economia de mercado dirigida. A política de segurança nacional impôs uma brutal repressão política e social sob coordenação do governo federal militar, o que garantiu que o crescimento industrial estimulado pelo Estado não se traduzisse em maior poder de barganha dos trabalhadores ${ }^{4}$. Pelo contrário, o resultado foi a elevação das desigualdades sociais e uma urbanização corporativa que convergiram para a multiplicação da criminalidade violenta. (MARICATO, 2001).

O processo constituinte de 1988 realizou pela primeira vez uma universalização de certos direitos, desvinculando-os do emprego formal para torná-los formalmente iguais para todos os cidadãos. Os movimentos sociais que emergiram nos últimos anos de ditadura e primeiros anos da transição buscaram a codificação formal e a efetivação concreta desses direitos por meio da mobilização coletiva. 
E de fato esses movimentos, em aliança ou confronto com os partidos e governantes eleitos, lograram vitórias parciais, que se revelam na gradual expansão da despesa social e com uma moderada redução das desigualdades, em especial sob os governos encabeçados pelo PT (2003-2016), que de fato fez crescer as despesas sociais num ritmo superior aos governos anteriores (Figura 1)

Figura 1 - Gasto social per capita BR 1995-2011 em valores de 2011

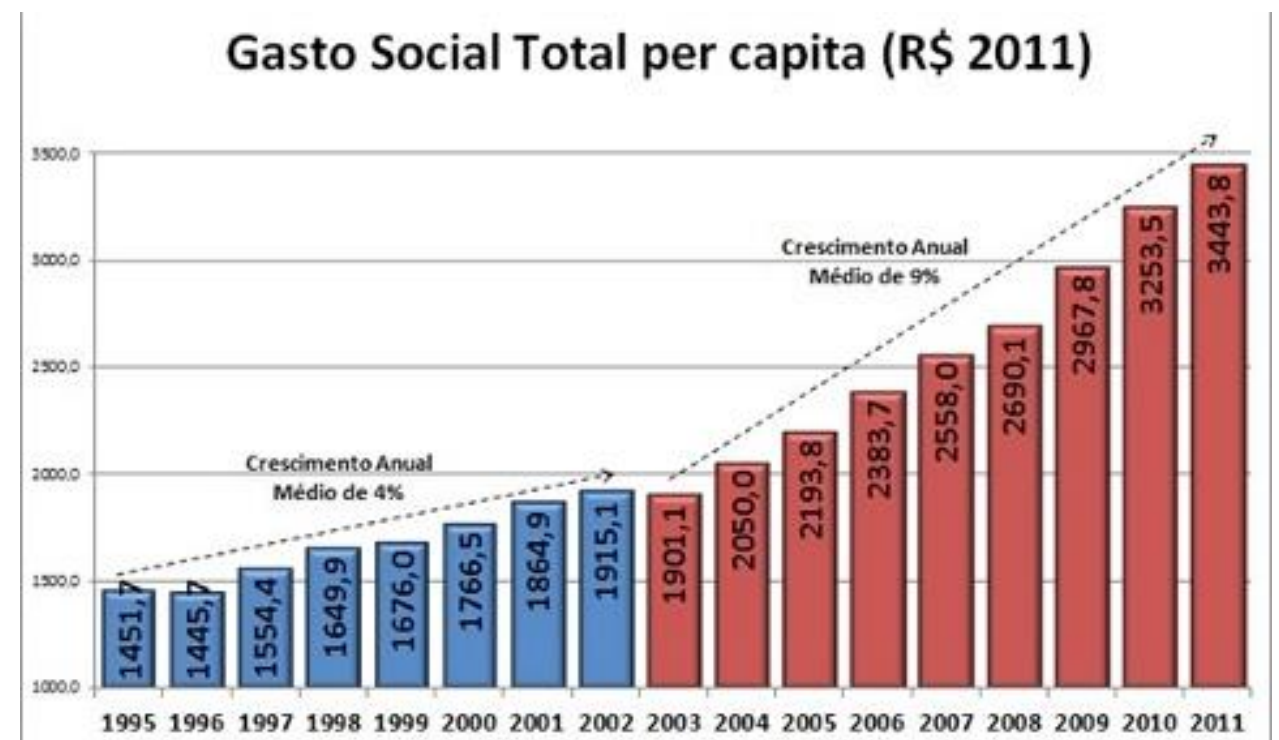

Fonte: MARIA, A. A "gastança" pública dez anos depois. Agência Envolverde, São Paulo, 2019. Disponível em: https://envolverde.cartacapital.com.br/a-gastaca-pública-dez-anos-depois/. Acesso em: 28 mar. 2018.

Por outro lado, é preciso atentar para alguns detalhes diferenciadores. Em primeiro lugar, a transição democrática não modificou de maneira significativa a organização policial militarizada e a tradição jurídica inquisitorial, herdado dos períodos anteriores, especialmente dos Anos de Chumbo. Segundo, no período de maior força do Consenso de Washington na condução da política econômica, também foi aprovado um dos principais instrumentos de expansão do encarceramento, a Lei de Crimes Hediondos (Lei $n^{0}$ 8072, de 25 de julho de 1990), que ampliou o uso da prisão provisória e restringiu benefícios penais ${ }^{5}$. Terceiro, se a Constituição de 1988 obrigava uma despesa social mínima em percentual do orçamento, a política financeira monetarista (o chamado tripé macroeconômico e a lei de responsabilidade fiscal) serviu como importante limitador para qualquer expansão da despesa social, que ficou subordinada aos objetivos do superávit primário. As dinâmicas de reestruturação industrial, estimuladas pela abertura comercial, não deixaram de atingir o mercado de trabalho brasileiro, gerando fragmentação da força de trabalho, ampliação do já hipertrofiado (pela informalidade) setor de serviços, aumento das terceirizações e, nos anos 1990 e início dos 2000, aumento do desemprego e da informalidade. (ANTUNES, 2004, 2009).

A situação mais contrastante com as análises desenvolvidas com base nos países centrais, porém, foi dos Governos Lula II e Dilma I, quando políticas públicas federais foram eficazes na redução 
do desemprego, da informalidade, da desigualdade de renda e da miséria, e ao mesmo tempo o encarceramento seletivo continuou se ampliando sobre as camadas marginalizadas (Figura 2). E um dos instrumentos, para tanto, foi a Lei de Drogas (Lei $n^{0} 11343$, de 23 de agosto de 2006) aprovada no primeiro mandato de Lula, com um projeto que pretendia medicalizar o usuário e punir com mais dureza o traficante, mas que acabou por colocar nas mãos da polícia a classificação dos suspeitos como traficantes ou usuários ${ }^{6}$. Produto de alianças provisórias entre bancadas e partidos divergentes sob a liderança do Partido dos Trabalhadores, os governos Lula e Dilma ampliaram a intervenção tanto social quanto penal em relação às classes populares, buscaram estimular medidas preventivas por meio do Programa Nacional de Segurança com Cidadania (PRONASCI) (BRASIL, 2007) e ao mesmo tempo mantiveram uma postura conservadora em relação às organizações policiais e à regulamentação das drogas, sem apoiar iniciativas reformistas mais significativas, como a desmilitarização da polícia ou a descriminalização do porte de drogas para o consumo.

Um exemplo interessante da relação entre política social e justiça penal poderia vir da relação entre o programa Bolsa-Família, de transferência condicionada de renda, e do encarceramento: ambos tiveram mais ou menos as mesmas camadas socioeconômicas como alvo, quais sejam, aquelas com maior vulnerabilidade social e reduzidas oportunidades de emprego (em razão da baixa escolaridade e discriminação racial), ficando às mulheres e crianças o benefício de renda condicional, $\mathrm{e}$ aos homens e jovens adultos o peso do cárcere, sendo legítima a hipótese de que muitas famílias pobres são impactadas ao longo do tempo (ou ao mesmo tempo) tanto pela assistência federal quanto pela criminalização e encarceramento. Num caso como no outro, como beneficiários de transferências de renda ou como submetidos ao cárcere, acabam sendo consumidores subsidiados. Nesse sentido, na análise da trajetória da população carcerária brasileira, além da óbvia sobre-representação de negros, jovens e de baixa escolaridade, um aspecto que chama a atenção é a importância do uso da prisão em flagrante e da prisão provisória e da repressão à circulação ilícita de mercadorias entre as camadas populares (crimes de drogas e contra o patrimônio), em detrimento da investigação criminal, das condenações judiciais e da repressão aos crimes contra a pessoa. ${ }^{7}$

\section{Figura 2 - Taxa de encarceramento por 100 mil habitantes no Brasil}




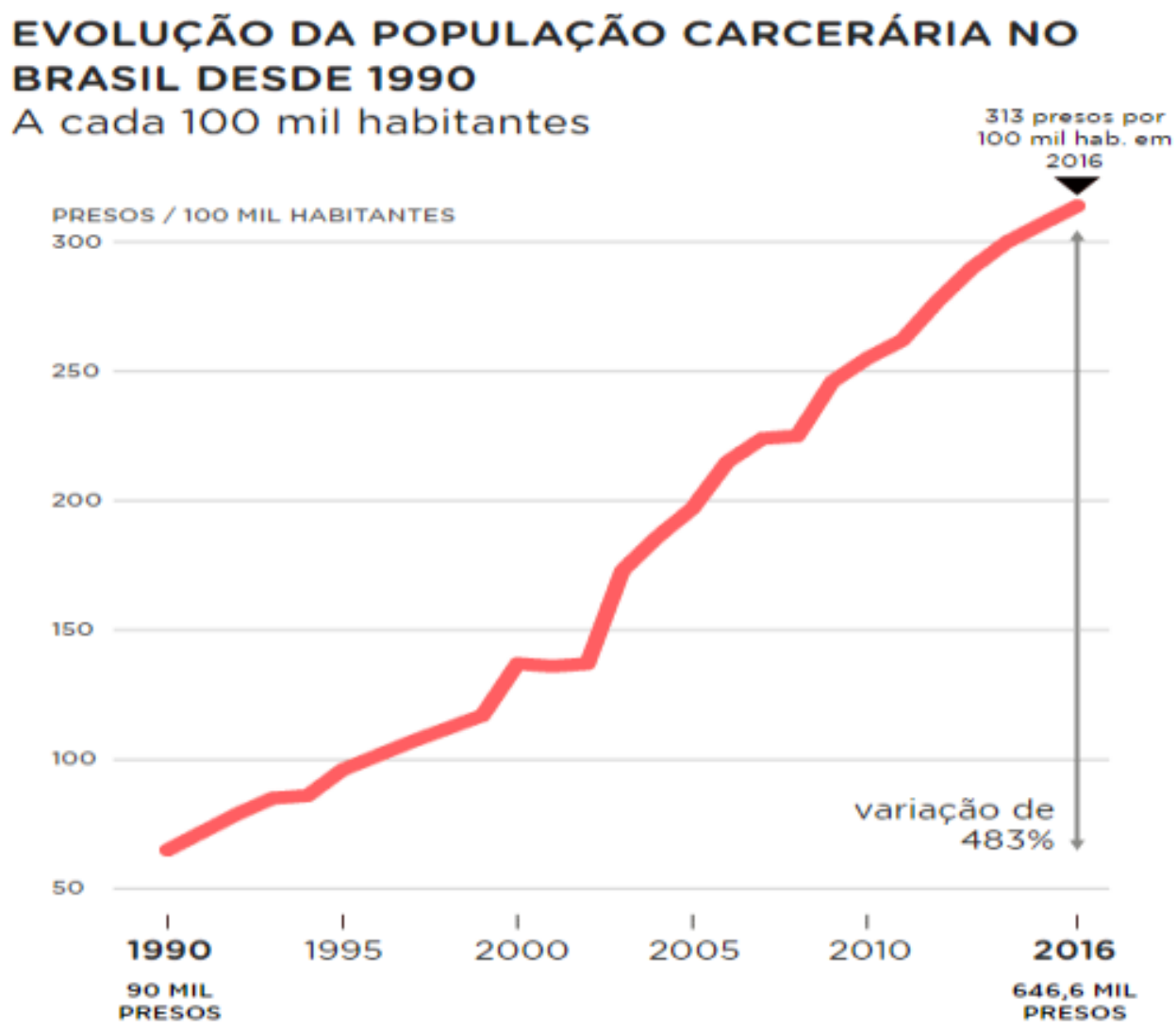

Fonte: MARIANI, D.; OSTETTI, V.; ALMEIDA, R. Lotação de presídios e taxa de encarceramento aqui e no mundo. Nexo, [S. I.], 2017. Disponivel em: https://www,nexojornal.com.br/grafico/2017/01/04/Lota\%C3\%A7\%C3\%A3o-depres\%C3\%ADdios-e-taxa-de-encarceramento-aqui-e-no-mundo. Acesso em: 28 mar. 2018.

É complexo averiguar até que ponto a postura dos governos Lula e Dilma em questão de segurança pública e de direito penal se deveu a uma predileção dos presidentes e do seu partido, e o quanto foram recuos, concessões ou omissões condicionadas pelas alianças parlamentares. É possível citar tanto a Lei de Drogas de 2006, sancionada por Lula, quanto o Projeto de Emenda Constitucional 51/13, que desmilitariza e reforma as polícias estaduais, proposto por um Senador petista.

A questão federalista deve ser levada em conta, uma vez que, se a legislação criminal é monopólio da União, a sua aplicação cotidiana está majoritariamente nas mãos de forças policiais (PM e PC), Ministérios Públicos e Judiciários estaduais: cerca de $75 \%$ do efetivo policial brasileiro é estadual, e os cárceres estaduais retêm $99,9 \%$ dos $\operatorname{presos}^{8}$. A arquitetura constitucional da segurança pública e justiça criminal, com sua divisão de competências e recursos, sugere que, em uma espécie de aliança tácita, um legislativo federal recrudescedor e governos e justiças estaduais repressivos foram os principais agentes da escalada punitiva e carcerária9 9 .

Ainda assim, não se deve isentar totalmente os governos Lula e Dilma de alguma participação na escalada punitiva. A análise do orçamento executado do PRONASCI demonstra que o investimento em treinamento, armas e veículos foi priorizado em relação aos projetos de prevenção social e comunitária (INSTITUTO DE ESTUDOS SOCIOECONÔMICOS, 2014). Legislações repressivas, 
como a Lei de Drogas (lei 11343 de 23 de agosto de 2006), a Lei das Organizações Criminosas (Lei ${ }^{0}$ 12694, de 24 de junho 2012 e Lei $n^{0}$ 12850, de 2 de agosto de 2013) e a Lei Antiterrorismo (Lei $n^{0}$ 13260, de 16 março de 2016) foram propostas e sancionadas pelo Executivo Federal nesse período. E o combate à impunidade, um dos cimentos ideológicos da cruzada punitiva, parece ter sido encampado pelas lideranças petistas ainda antes da vitória na eleição presidencial de $2002^{10}$. Como relacionar esse punitivismo politicamente correto com uma política econômica de combate ao desemprego, à informalidade e à desigualdade salarial? Uma possível conexão seria a afinidade eletiva entre a lógica da inclusão pelo consumo privado, o que foi efetivamente promovido pelos governos Lula e Dilma, e a lógica do mérito e culpa individuais implícita numa ideia de cidadania como direitos do contribuinte. Segundo essa cidadania do contribuidor, descrita por Holston (2013), os direitos de cidadão precisam ser conquistados com esforço e sacrifício, adquirindo um sentido de mérito moral individual, obtido por meio do acesso à condição particular de consumidor e contribuinte. Apesar de mais abrangente, ao menos num período de expansão do consumo popular (como foram os governos Lula e Dilma), essa visão não deixa de produzir seus marginalizados, na figura daqueles que supostamente não consomem nem contribuem por esforço próprio para o crescimento do mercado e do Estado, e que por isso não mereceriam direitos, por exemplo, a população de rua ou aqueles que dependem da assistência federal para a subsistência familiar.

As mudanças não devem ser nem superestimadas nem subestimadas. A legislação administrativa e penal que regulamenta a segurança pública e justiça penal ainda preserva parte do conteúdo imposto pelo Estado Novo e pela Ditadura Militar. E a previdência social, em grande parte regida ainda pelo que Santos (1979) chamou de cidadania regulada, ainda é o programa social com maior orçamento. Por outro lado, não se deve ignorar a crescente importância das leis de Crimes Hediondos de 1991, e, de Drogas de 2006, na administração da justiça criminal, nem as iniciativas federais, estaduais e municipais que buscaram construir programas de segurança pública, orientadas por concepções diversas da questão. No posterior período de crise econômica e política, a partir de 2015, a situação que era paradoxal, quando conviviam políticas contraditórias dentro do mesmo governo, parece ter se desenvolvido no sentido de uma polarização ideológica radicalizada depois do controverso processo de impeachment de Dilma Rousseff. A contradição latente tornou-se, assim, um conflito aberto entre perspectivas punitivas e inclusivas de governo da pobreza e da violência.

\section{CONCLUSÃO}

Buscamos refletir sobre os processos de gestão da miséria no capitalismo periférico e tardio por meio de uma discussão bibliográfica inicial e da pesquisa documental. Na primeira, resgatamos a relação entre trabalho e punição presente na sociologia clássica, tanto na tradição durkheimeana quanto 
na tradição marxista. A primeira enfatizou o conteúdo simbólico e expressivo das penalidades, como veículo de afirmação das crenças coletivas na punição do desviante, enquanto a segunda ressalvou 0 caráter estratégico dos dispositivos punitivos na organização da dominação de classe, e, por conseguinte, a correspondência relativa entre modo de produção e instituições penais. Ao abordar a punição como um dispositivo de poder-saber (poder que produz saber, e saber que serve ao poder), a perspectiva foucaultiana revela o vínculo entre as práticas institucionalizadas de exercício de poder e 0 discurso de ciências como a criminologia, a psiquiatria e a jurisprudência.

A sociologia do trabalho, por sua vez, apresentou uma importante análise dos regimes de regulação das relações entre Estado, capital e trabalho, apontando no sentido de uma estruturação intermediária entre o evento de curta duração e o modo de produção de longa duração. Tais regimes de regulação e acumulação precisavam lançar mão de instrumentos sociais e penais de acordo com exigências e interesses dominantes, num conflituoso ajuste mútuo entre agentes estatais, capitalistas e trabalhadores, sempre, é claro, no sentido de uma reprodução ampliada da acumulação de capital.

Assim, o diálogo entre a sociologia da punição e a sociologia do trabalho permite, de um lado, a redescoberta dos vínculos macroprocessuais dos dispositivos punitivos e de controle social. Uma sociologia pura do crime e da punição tende a se fixar em dinâmicas organizacionais internas aos órgãos policiais e judiciários e aos mercados ilegais, esquecendo das suas conexões com a estrutura socioeconômica mais ampla que, no final das contas, é pressuposta pela existência dessas organizações repressivas e mercados ilegais. Por outro lado, a sociologia da punição auxilia na análise dos mecanismos disciplinares que subordinam a força de trabalho e chamam a atenção para outros tipos de trabalho negligenciados nessa área, como o do pessoal das forças de segurança pública ou das atividades ligadas à economia criminosa, bem como a analogia (e homologia) entre a organização interna dos dispositivos de trabalho e de punição, possibilitando uma análise mais sofisticada dos mecanismos de dominação social.

No Brasil, a conexão entre política social e justiça penal, no período republicano, foi discutida rapidamente, tomando como etapas a política de industrialização por substituição de importações, pela qual o Estado buscou integrar de maneira subordinada os assalariados urbanos ao projeto desenvolvimentista, por meio de uma combinação de benefícios sociais condicionados pelo emprego formal, de um lado, e de repressão policial aos vadios e subversivos, de outro. Primeiramente numa versão populista, quando se buscava dosar a distribuição e a repressão, e posteriormente numa versão elitista, quando a repressão política esvaziou a reivindicação trabalhista, aprofundando as desigualdades sociais por meio da intensificação da coerção política. Ao longo dessas décadas, foi estabelecida e enraizada uma concepção de cidadania diferenciada e regulada, pela qual o acesso da grande maioria aos direitos é condicionada por exigências legais, como o contrato de trabalho 
formalizado em profissões regulamentadas, diplomas de ensino superior, títulos de propriedade particular e relações pessoais com ocupantes de cargos de poder, de tal maneira que grande parcela da população se encontrava, na prática, excluída de garantias legais e materiais de cidadania, e, entre os incluídos, havia uma diferenciação bastante marcada, e muitas vezes legalmente codificada e politicamente negociada.

A constituinte democrática de 1988 trouxe uma reformulação universalista e igualitária da cidadania civil e social. No entanto, sua efetivação foi duplamente tolhida. De um lado, os direitos civis de camadas consideráveis da população foram esvaziados pela restrição do acesso à justiça e práticas policiais e judiciais autoritárias, legitimadas por um discurso belicista de lei e ordem. De outro, os investimentos sociais foram limitados e subordinados pela gestão macroeconômica restritiva, em nome do combate à inflação e da responsabilidade fiscal. O período mais paradoxal, nesse sentido, foi o dos governos Lula e Dilma, quando a ampliação da despesa social federal coexistiu com a expansão seletiva do encarceramento. Situação contraditória, para a qual podem ter concorrido diversos fatores, do presidencialismo de coalizão aos paradoxos da inclusão pelo consumo, passando pela rigidez do próprio modelo instituído de segurança pública, em grande parte herdado dos regimes autoritários e pouco revisados durante o processo constituinte-democrático. Essa coexistência dos contrários dentro dos governos federais nos fornece algumas pistas para compreender o posterior processo de polarização em meio à crise econômica e política da Nova República, crise esta radicalizada pelo controverso impeachment de Dilma Rousseff e ascensão de um grupo político radicalmente comprometido com a retomada da agenda econômica liberal.

\section{REFERÊNCIAS}

ANTUNES, R. Anotações sobre o capitalismo recente e a reestruturação produtiva no Brasil. In ANTUNES, R. 0 avesso do trabalho. São Paulo: expressão popular, 2004. p. 13-28.

ANTUNES, R. Os sentidos do trabalho: ensaio sobre a afirmação e a negação do trabalho. 2. ed. São Paulo: Boitempo, 2009.

BAYLEY, D. H. Padrões de policiamento: uma análise internacional comparativa. São Paulo: Edusp, 2001.

BONI BITTENCOURT, M. Gestão punitiva da insegurança: do esquadrão da morte às masmorras high tech. Curitiba: Ed. Prismas, 2017.

BRASIL. Congresso Nacional. Câmara dos Deputados. Relatório final da Comissão Parlamentar de Inquérito destinada a investigar o Sistema Carcerário. Brasília, DF, 2009.

BRASIL. Conselho Nacional do Ministério Público. A visão do Ministério Público sobre o sistema prisional brasileiro. Brasília, DF, 2013b. 
BRASIL. Ministério da Justiça. Conselho Nacional do Ministério Público. Secretaria Nacional de Segurança Pública. Diagnóstico da investigação de homicídios no país. Brasília, DF, 2012.

BRASIL. Ministério da Justiça. Secretaria Nacional de Segurança Pública. Caracterização dos recursos físicos e humanos dos órgãos estaduais de segurança pública (2003-2006). Brasília, DF, 2006.

BRASIL. Perfil das instituições de segurança pública. Brasília, DF, 2013a.

BRASIL. Presidência da República. I Plano Nacional de Segurança Pública. Brasília, DF, 2000.

BRASIL. Presidência da República. Programa Nacional de Segurança com Cidadania (PRONASCI). Brasília, DF, 2007.

CAMPOS, M. da S. Crime e Congresso Nacional: uma análise da política criminal aprovada de 1989 a 2006. Revista Brasileira de Ciência Política, Brasília, DF, n. 15, p. 315-347, 2014.

CAMPOS, M. da S.; ALVAREZ, M. C. Pela metade: Implicações do dispositivo médico-criminal da "Nova" Lei de Drogas na cidade de São Paulo. Tempo Social, São Paulo, v. 29, n. 2, p. 45-74, 2017. Disponível em: http://www.scielo.br/scielo.php?script=sci_arttext\&pid=S0103$20702017000200045 \&$ Ing=en\&nrm=iso. Acesso em: 28 ago. 2017.

CASTEL, R. As metamorfoses da questão social: uma crônica do salário. Petrópolis, RJ: Vozes, 1998.

DE GIORGI, A. A miséria governada através do sistema penal. Rio de Janeiro: Revan/ICC, 2006.

DECCA, E. S. de. A ciência da produção: fábrica despolitizada. Revista Brasileira de História, São Paulo, v. 3, n .6, p. 47-79, 1984.

DIAS NETO, T. Policiamento comunitário e controle sobre a polícia: a experiência norte-americana. Rio de Janeiro: Lumens Juris, 2003.

DURKHEIM, É. "Da divisão do trabalho social". In COMTE, A.; DURKHEIM, É. Textos escolhidos. São Paulo: Abril Cultural, 1973.

FORUM BRASILEIRO DE SEGURANÇA PÚBLICA. Anuário do Fórum Brasileiro de Segurança Pública. São Paulo, 2007-2016.

FOUCALT, M. Vigiar e punir: o nascimento da prisão. Trad. Raquel Ramalhete. 41. ed. Petrópolis, RJ: Vozes, 2013.

FOUCAULT, M. A verdade e as forças jurídicas. Rio de Janeiro: NAU editora, 2003.

FOUCAULT, M. Vigiar e punir. Petrópolis, RJ: Vozes, 2009.

GARLAND, D. A cultura do controle: crime e ordem social na sociedade contemporânea. Rio de Janeiro: Revan, 2008.

GOUNET, T. Fordismo e toyotismo. São Paulo: Boitempo , 1999. 
HALL, P. A., TAYLOR, R. C. R. As três versões do neo- institucionalismo. Lua Nova: Revista de Cultura e Política, São Paulo, n. 58, p.193- 223, 2003.

HARVEY, D. Condição pós-moderna. São Paulo: Edições Loyola, 1992.

HOLSTON, J. Cidadania insurgente: disjunções da democracia e da modernidade no Brasil. São Paulo: Companhia das Letras, 2013.

INSTITUTO BRASILEIRO DE GEOGRAFIA E ESTATÍSTICA. Síntese de Indicadores Sociais 2014. Rio de Janeiro, 2015. (Estudos e Pesquisas - Informação Demográfica e Socioeconômica, n. 35).

INSTITUTO DE ESTUDOS SOCIOECONÔMICOS. Segurança pública e cidadania: uma análise orçamentária do PRONASCI. Brasília, DF, 2014. Disponível em:

http://www.cfemea.org.br/images/stories/publicacoes/seguranca_publica_cidadania.pdf. Acesso em: 14 fev. 2018.

KALECKI, M. Aspectos políticos do pleno emprego: palestra dada à Sociedade Marshall em Cambridge na primavera de 1942. Jornal GGN (online), [S. I.], 2015. Entrevista concedida a Lourdes Nassif.

Disponivel em: https://jornalggn.com.br/gestao/aspectos-politicos-do-pleno-emprego-por-michal-kalecki/. Acesso em: 28 mar. 2018.

LINS, P. Cidade de Deus. São Paulo: Companhia das Letras, 2007.

MARGLIN, S. Origem e funções do parcelamento das tarefas (para que servem os patrões?). In GORZ, A. Critica da divisão do trabalho. São Paulo: Martins Fontes, 1980.

MARIA, A. A "gastança” pública dez anos depois. Agência Envolverde, São Paulo, 2019. Disponível em: https://envolverde.cartacapital.com.br/a-gastaca-pública-dez-anos-depois/. Acesso em: 28 mar. 2018.

MARIANI, D.; OSTETTI, V.; ALMEIDA, R. Lotação de presídios e taxa de encarceramento aqui e no mundo. Nexo, [S. I.], 2017. Disponível em:

https://www,nexojornal.com.br/grafico/2017/01/04/Lota\%C3\%A7\%C3\%A30-de-pres\%C3\%ADdios-e-taxade-encarceramento-aqui-e-no-mundo. Acesso em: 28 mar. 2018.

MARICATO, E. Brasil, cidades: alternativas para a crise urbana. Petrópolis, RJ: Vozes, 2001.

MARX, K. O capital: crítica da economia política. Rio de Janeiro: Civilização Brasileira, 2006.

MELOSSI, D.; PAVARINI, M. Cárcere e fábrica: as origens do sistema penitenciário (séculos XVI-XIX). Rio de Janeiro: Revan/ICC, 2006.

NEFFA, J. C. El proceso de trabajo y la economia del tiempo: contribuición al analisis crítico de K. Marx, F.W. Taylor y H. Ford. Buenos Aires: Humanitas, 1990.

RUSCHE, G.; KIRCHHEIMER, O. Punição e estrutura social. Rio de Janeiro: Freitas Bastos, 1999.

SANTOS, W. G. Cidadania e justiça: a política social na ordem brasileira. Rio de Janeiro: Campus, 1979 
SINHORETTO, J.; SILVESTRE, G.; MELO, F. A. L. de. O encarceramento em massa em São Paulo. Tempo Social, São Paulo, v. 25, n. 1, p. 83-106, 2013. Disponível em: http://www.scielo.br/scielo.php?script=sci_arttext\&pid=S0103-20702013000100005\&lng=en\&nrm=iso. Acesso em: 6 ago. 2017.

SOARES, L. E. Meu casaco de general: 500 dias no front da segurança pública no Rio de Janeiro. São Paulo: Companhia das Letras, 2000.

THOMPSON, E. P. Tempo, disciplina de trabalho e o capitalismo industrial. In: THOMPSON, E. P. Costumes em comum. São Paulo: Companhia das Letras, 1998.

VARELLA, D. Carcereiros. São Paulo: Companhia das Letras, 2012.

VARELLA, D. Estação Carandiru. São Paulo: Companhia das Letras, 2005.

VARELLA, D. Prisioneiras. São Paulo: Companhia das Letras, 2017.

WACQUANT, L. As duas faces do gueto. São Paulo: Boitempo, 2008.

WACQUANT, L. As prisões da miséria. Rio de Janeiro: Jorge Zahar, 2001a.

WACQUANT, L. Os condenados da cidade. Rio de Janeiro: Revan; FASE, 2001b.

WACQUANT, L. Punir os pobres: A nova gestão da miséria nos Estados Unidos [A onda punitiva]. Rio de Janeiro: Revan/ICC, 2007.

YOUNG, J. A sociedade excludente: eclusão social, criminalidade e diferença na modernidade recente. Trad. Renato Aguiar. Rio de Janeiro: Revan; IBCCrim, 2002.

\section{Notas}

${ }^{1}$ Em grande parte coletados e analisados em função da pesquisa de mestrado do Autor.

2 No romance Cidade de Deus (LINS, 1997) um dos personagens, um ladrão contumaz, arrumou um emprego como pedreiro por alguns poucos meses, para que assim tivesse uma carteira de trabalho assinada e mãos calejadas, as quais poderiam ser apresentadas à polícia como prova de que era um trabalhador honesto e não merecedor de suspeitas.

3 Lei 5107 de 13 de setembro de 1966, regulamentada pelo Decreto n 59820, de 20 de dezembro de 1966.

4 É o dilema posto por Kalecki (2015), noutro contexto, ao perguntar porque o empresariado não apoiava a geração de emprego via investimento público sob regimes democráticos, mas apoiava a expansão fiscal sob ditaduras: é que, entre outras considerações, o pleno emprego reduz a disciplina de mercado pela ameaça da demissão e aumenta o poder de barganha e organização dos trabalhadores. Por outro lado, "[...] a aversão a política de gastos do governo, como tal, é superada sob o fascismo pelo fato de que a máquina do Estado está sob o controle direto de uma parceria das grandes empresas com o fascismo. A necessidade do mito das 'finanças saudáveis', que servira para impedir o governo de causar uma crise de confiança devido aos gastos públicos, é removida. Em uma democracia, não se sabe como será o próximo governo. Sob o fascismo não há próximo governo. A antipatia aos gastos do governo, seja em investimento público ou consumo, é superada pela concentração dos gastos governamentais em armamentos. Finalmente, a 'disciplina nas fábricas' e a 'estabilidade política' sob o pleno emprego são mantidas pela 'nova ordem', que varia de supressão dos sindicatos aos campos de concentração. A pressão política substitui a pressão econômica do desemprego." (KALECKI, 2015, p. 58).

5 Para uma análise da legislação criminal aprovada pelo Congresso Nacional, ver Campos (2014). 
${ }^{6}$ Sobre a aplicação da Lei de Drogas de 2006, ver Campos e Alvares (2017).

${ }^{7}$ Remeto à análise da trajetória da população carcerária feita por Sinhoretto, Silvestre e Melo (2015). A relação entre a trajetória de indicadores de encarceramento e de indicadores socioeconômicos (ao nível nacional e para o caso específico do Estado do Espírito Santo) pode ser lida com maior detalhe em Boni Bittencourt (2017). A trajetória da população carcerária feminina torna 0 argumento bastante relativo - no entanto, o peso dos números totais indica que 0 sistema carcerário segue tendo uma clientela esmagadoramente masculina.

8 Os Anuários do Fórum Brasileiro de Segurança Pública (2007-2016) são fonte destes números. As proporções parecem se manter constantes ao longo do tempo.

9 Essa análise parece se confirmar em relação ao Estado de São Paulo, maior encarcerador em termos absolutos (SINHORETTO; SILVESTRE; MELO, 2013), e ao Estado do Espírito Santo, o que mais expandiu o encarceramento em termos relativos (BONI BITTENCOURT, 2017).

10 Ver o Projeto Segurança Pública (2001-2002). 